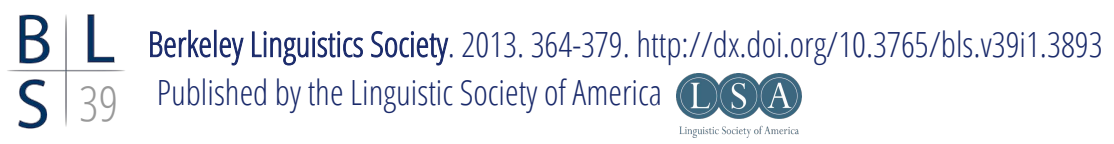

\title{
The Expression of Motion Events: A Quantitative Study of Six Typologically Varied Languages
}

\author{
BENJAMIN FAGARD ${ }^{\mathrm{i}}$, JORDAN ZLATEV ${ }^{\mathrm{ii}}$, ANETTA KOPECKA ${ }^{\mathrm{iii}}$, \\ MASSIMO CERRUTI ${ }^{\text {iv }} \&$ JOHAN BLOMBERG ${ }^{\text {ii }}$ \\ Lattice, Montrouge, France (CNRS \& ENS) ${ }^{i}$; Cognitive Semiotics, Lund \\ University $^{i i} ;$ DDL \& Université Lyon $2^{i i i}$; Università degli Studi di Torino ${ }^{i v}$
}

\section{Introduction}

More than two decades of intense research on motion event typology, emanating from the influential proposal of Talmy $(1991,2000)$ of a universal binary classification of languages into verb-framed (VF), such as French, and satelliteframed (SF), such as English, still leaves many questions unresolved. One such question is whether serial-verb languages such as Thai should be considered a third type (Zlatev and David 2003; Zlatev and Yangklang 2004), generalized by Slobin (2004) as equipollently-framed (EF). The basis for this distinction is that, while VF languages readily express the semantic category PATH (or more generally, "the core schema", cf. Talmy 2000) in their main verbs, leaving MANNER to be expressed optionally, as in French (1), SF languages typically express MANNER in their verbs, leaving PATH for verb-particles or verb-prefixes, jointly called satellites, as in (2), and EF languages easily combine verbs expressing MANNER, PATH, and DEIXIS, as in Thai (3).
(1) Il est entré dans la maison (en courant) (French) 3SG.M AUX enter.PST in DEF house in run.PART
'He ran into the house.'
(2) He ran into the house
(English) 


\section{Benjamin Fagard et al.}

\section{(3) kháw wîy khâw pay nay bâan \\ $3 \mathrm{SG}$ run enter go in house \\ 'He ran into the house.'}

A second question is whether these two or three types should be regarded as in some sense 'distinct' (even if they have minor expression patterns conflicting the dominant, type-characteristic ones), or rather as forming continua with respect to certain dimensions, such as the propensity to express MANNER (Slobin 2004) or PATH (Ibarretxe-Antuñano 2009). A third and related question is whether the notion of language types (with respect to motion typology or in general) should not be abandoned, and languages rather be described as conglomerates of constructions and strategies, with complex overlaps (Kopecka 2006; Beavers, Levin \& Tham 2010; Croft et al. 2010). We should add that, with the advent of enhanced usage-based methods such as corpus analysis and elicitation, the tendency to answer the latter two questions in the direction of continua and (even individual) ${ }^{1}$ strategies rather than types has increased. A fourth question concerns conceptual issues, such as what exactly should be regarded as MOTION, PATH, and MANNER, since the way in which these concepts are defined, both theoretically and operationally, will inevitably affect the results from empirical investigations (Zlatev, Blomberg and David 2010; Fortis et al. 2011). A fifth and final question concerns the structural issue of satellites (Imbert et al. 2011), defined by Talmy (2000:102) as a constituent standing in a 'sister relation to the verb root.' It remains to be shown if, for instance, Germanic verbal particles (e.g. Swedish gå in 'to go in') function similarly to Slavic verb-prefixes (e.g. Bulgarian v-liza 'in$\left.?^{, 2}\right)$.

In the research reported here, we address these questions, using an empirical approach based on elicited data from six carefully chosen languages. Two of these are the Romance languages French and Piedmontese, which can both reasonably be expected to be of the VF type. ${ }^{3}$ We also analyzed the Germanic languages Swedish and German and the Slavic language Polish, all three typically considered as SF. Finally, we included Thai (Tai-Kadai), classified as EF by Slobin (2004). In Section 2, we describe the general theory of spatial semantics that we depart from, which provides the basis for defining the key semantic concepts we focus on: MANNER, PATH, and DEIXIS. In Section 3, we describe our methodology, and the expectations which emanate from previous research. Section 4 presents our findings with respect to the three main semantic categories,

\footnotetext{
${ }^{1}$ Individual variation in our data is represented in Figures (14), (15), (22), (23), (26), and (27) in section 4 , which indicate standard deviations between participants, for each language.

${ }^{2}$ The verb *liza (without a prefix) does not exist: the compound verb is lexicalized and partly opaque.

${ }^{3}$ Note, however, that some Italo-Romance dialects have been classified as SF (Iacobini 2012); there is to date no specific study on the VF or SF nature of Piedmontese.
} 


\section{The Expression of Motion Events}

discussing both expected and unexpected results. Finally, in Section 5, we sum up by presenting tentative answers to the questions outlined above.

\section{Theory and concepts}

The theoretical framework adopted here is holistic spatial semantics (Zlatev 2003, 2007), a theory of the linguistic expression of spatial meaning which attempts to strike a balance between (embodied) universalism and language-specificity. It claims that the minimal unit of spatial analysis is the whole (trans)locative utterance, where the meaning of the parts is dependent on the whole utterance and vice-versa. Spatial semantic categories are assumed to be based on pre-linguistic bodily experience, but language-specifically conventionalized. The theory proposes that seven universal spatial semantic categories are necessary and jointly sufficient to characterize the core semantics of a locative or translocative utterance: Trajector, Landmark, Motion, Region, Frame of Reference (FoR), PATH, and DIRECTION. Especially relevant for present purposes are the final three.

The spatial disposition of the TRAJECTOR (FIGURE) is always situated within one or more FRAMES OF REFERENCE (FoR) defined by one or more reference points and axes. Depending on the nature of the latter, three general kinds of FoR may be distinguished (generalizations of those proposed by Levinson 2003, cf. Zlatev 2007). The VIEWPOINT-CENTERED FoR involves utterances where the main reference point is a deictic center (henceforth DC) as in (4), or else involves an explicit ("objectified") viewpoint as in (5). The OBJECT-CENTERED FoR always involves a landmark, including both landmarks with "intrinsic" orientations as in (6), and without, as in (7). The GEOCENTRIC FoR involves relatively fixed ("absolute") reference points or axes, on either the horizontal (8) or the vertical plane (9). On this basis, the category DIRECTION is defined as a vector along one of the axes provided by a FoR as in (10).

(4) The woman is coming this way

(5) The house is to the left, from your point of view

(6) Stand in front of me

(7) He went into the room

(8) Go west

(9) He climbed up the stairs

(10) The plane is flying...

a. that way

FoR: VIEWPOINT-CENTERED

b. $\quad$ North

FoR: GEOCENTRIC

c. towards the North pole FoR: OBJECT-CENTERED 


\section{Benjamin Fagard et al.}

On the basis of the cross-linguistic generalization that unrelated languages systematically distinguish between (at least) three components of a motion event, PATH is defined as having one or more of the following possible values: Begin, Middle, and End, as shown in (11). As may be noted, PATH implies an OBJECTCENTERED FoR.

(11) a. Bill went out of the room

b. Bill went through the room

c. Bill went into the room

d. Bill went out of the office into the lecture hall
PATH: Begin

PATH: Middle

PATH: End

PATH: Begin+End

The "holism" of the theory is reflected in two respects. First, the mapping between the semantic categories and the form classes expressing them (such as noun, verb, adposition, verb-prefix, verb-particle, case-marking) are in general many-to-many, thus resulting in patterns of conflation (Talmy 1985) and distribution (Sinha and Kuteva 1995). Second, the division of labor between semantics (conventional meaning) and pragmatics (contextual specification) is expected to vary from language to language, but in general the meaning of the whole utterance will not be derivable from the individual mappings, but depend on more global knowledge frames. The present study is part of a more general research project applying the general concepts and hypotheses of Holistic spatial semantics to the description of a sample of the world's languages, with the goal of obtaining a novel, theoretically and empirically consistent motion event typology.

\section{$3 \quad$ Methodology}

\subsection{Stimuli}

For the purpose of eliciting descriptions of motion events, we used a series of video-clips showing male and female agents in natural settings, engaged in actions and translocations. These clips were designed by the research group Trajectoire (Ishibashi, Kopecka and Vuillermet 2006). There were 76 such clips in total, including 2 warm-up clips, 55 target clips showing translocative motion events, and 19 clips showing other (non-translocative) activities. ${ }^{4}$ The stimuli were appropriate for our purpose since they were designed to vary according to parameters such as the following: (a) PATH of motion: Begin, Middle, End; (b) DIRECTION of motion: towards the camera, away from the camera, sideways; (c) MANNER of motion: walking, running, jumping; (d) Boundary-crossing: presence

\footnotetext{
${ }^{4}$ Zlatev, Blomberg and David (2010) explicate the difference between translocative and nontranslocative motion, which approximately correspond to "translational" and "self-contained" motion (Talmy 2000), respectively.
} 


\section{The Expression of Motion Events}

or absence. A full description of the elicitation tool can be found in Kopecka and Ishibashi (2011).

\subsection{Languages, speakers and elicitation}

Overall, 84 participants were included in the study, distributed across languages as shown in (12) below, which presents the size of collected and analyzed data (limited to target descriptions). As pointed out in Section 1, these six languages can be seen to represent the three major languages types SF (German, Swedish, Polish), VF (French, Piedmontese) and EF (Thai), which makes them a good test-bench for the questions outlined in the introduction. Elicitation was conducted in the homeland of participants, except for Thai where data was gathered in Lund, Sweden. In all cases, the investigator conducted the study using the target language, except for Piedmontese, where the study was conducted in Italian.

All participants were asked to briefly describe each scene after viewing it, telling the investigator "what had happened" in the video-clip. These descriptions were either video- or audio-recorded.

(12) The data analyzed for the present study

\begin{tabular}{|c|c|c|c|c|}
\hline Type & Language & Speakers & $\begin{array}{c}\text { Target } \\
\text { descriptions }\end{array}$ & $\begin{array}{r}\text { Total } \\
\text { words }\end{array}$ \\
\hline $\mathrm{EF}$ & Thai & 14 & 700 & 7080 \\
\hline $\mathrm{SF}$ & Polish & 14 & 699 & 5766 \\
\hline SF & German & 18 & 968 & 15655 \\
\hline $\mathrm{SF}$ & Swedish & 17 & 838 & 8297 \\
\hline $\mathrm{VF}$ & French & 11 & 536 & 9972 \\
\hline $\mathrm{VF}$ & Piedmontese & 10 & 486 & 4306 \\
\hline \multicolumn{2}{|c|}{ Total } & 84 & 4227 & 51076 \\
\hline
\end{tabular}

\subsection{Data analysis}

An exhaustive transcription was performed, except for noises, interruptions, and comments (such as "I'm tired", "This is boring", "That's fun") on the basis of the audio or video files in the standard orthography of the language. For Thai, this was followed by an additional step of automatic transliteration into Latin orthography. Each of the descriptions was then coded manually for MANNER, PATH, and DEIXIS.

MANNER is not part of the (motion) "core schema" (Talmy 2000), but rather a qualification of the motion event with respect to aspects such as bodily locomotion: Polish biegnacy 'running,' velocity: Swedish raskt 'fast,' motion 


\section{Benjamin Fagard et al.}

shape: French courbe 'curved,' motion style: German zielgerichtet 'aimed at the goal, decided,' betont cool 'very relaxed,' Polish ostrożny 'careful.' We coded for the presence of at least one such element in each utterance. Most MANNER expressions concerned bodily locomotion in all six languages, mostly expressed in verbs.

As explained in Section 2, a schematic notion of PATH was adopted, involving the values Begin, Middle, End, depending on whether the translocation departed from, crossed, or ended at a salient LANDMARK. When a landmark served as a "beacon" (either towards which a motion is directed, or from which it comes) this was analyzed as DiRECTION; such examples are not reported in what follows. Similarly for cases in which translocation was described as proceeding along a vertical dimension (GEOCENTRIC FoR).

The only sub-type of DIRECTION (and VIEWPOINT-CENTERED FoR) on which we focus here is DEIXIS. The most common and relevant way of expressing it in our corpus is with a deictic verb denoting motion towards the speaker. We therefore coded the presence or absence of Thai ma, German kommen, Swedish komma, French venir, Piedmontese vene 'to come,' as well as that of French revenir 'to come back' and provenir 'to come (from).' Verbs denoting motion away from the speaker (such as English go) are known to be less linked to the expression of DEIXIS (Wilkins \& Hill 1995), and to take on various other meanings. Still, we also coded the presence of Thai pai, French aller, German gehen, Swedish gå, and Piedmontese andé 'to go,' in order to check the validity of these assumptions. ${ }^{5}$ The presence or absence of deictic adverbs such as here and there was coded, but not included in the analysis below, since their use was most often pragmatic, temporal or discourse-oriented, especially when they were found in utterance-initial uses, as in (13).

\section{(13) Tutaj mamy mężczyznę który uprawia jogging (Polish) here have.1PL man.ACC who.M practice.3sG jogging 'Here we have a man doing his jogging' (traj037_pol12) ${ }^{6}$}

Overall, each one of the three semantic categories MANNER, PATH, and DEIXIS could be expressed, in every scene description (which could consist of several sentences), by one or more of the following form-classes: verb, adverb, verb-

\footnotetext{
${ }^{5}$ Since Polish has no specific COME or GO verb, verbally expressed Deixis in the language could only be linked to the use of verbal prefixes, known to be partially grammaticalized into deictic markers in Slavic languages (Ricca 1993).

${ }^{6}$ References to examples taken from our database indicate the number of the stimulus (here "traj037"), the language (here "pol" for Polish) and the participant ID (here "12").
} 


\section{The Expression of Motion Events}

prefix, ${ }^{7}$ verb-particle, prepositional phrase, adjective, case marker, preposition, and pronoun. Due to space limitations, we do not here describe the particular patterns of mapping between semantic categories and form-classes, ${ }^{8}$ but simply report on the frequency of expression of these three semantic categories.

\subsection{Expectations}

In theory, SF languages should have a higher proportion of MANNER expression than VF languages. Since the place of EF languages such as Thai remains uncertain, a tentative prediction - especially from a perspective emphasizing continua - is that it would be intermediate. This difference between SF and VF can be expected to be most clear in the cases where MANNER is "unmarked", e.g. in the case of walking as opposed to jumping.

In contrast to MANNER, there is no reason to suppose large differences in PATH expression, since what varies among the languages are the preferred ways in expressing it: through verbs in Thai and the VF languages, and through satellites in the SF languages. Previous studies have reported on a much more detailed specification of PATH in SF than VF languages (e.g. Berman and Slobin 1994:118), but they included DIRECTION as a subtype of PATH. Since satellites often express DIRECTION, it is unclear if there should be any difference with respect to PATH proper.

DEIXIS has been something of a blind spot in the motion event literature, at least until recently (e.g. Nakazawa 2006). In many previous studies, for instance, verbs denoting motion towards or away from the DC were not distinguished from path verbs like cross. Based on previous research (Zlatev and Yangklang 2004), we could expect higher proportions of DEIXIS in Thai than in the other languages, due to a dedicated "slot" for a deictic verb in the serial verb construction, as in (3). On the other extreme, Polish, which has no lexicalized deictic verb, was expected to mark DEIXIS only rarely.

\section{$4 \quad$ Results and discussion}

With respect to MANNER, as shown in (14), we found a clear difference in its frequency of expression between the three SF languages and the two VF languages. This difference was highly significant $\left(\mathrm{chi}^{2}=914, \mathrm{p}<.001\right)$.

\footnotetext{
${ }^{7}$ The class verb-prefix covered both inseparable prefixes such as German be- (betreten 'step in', with e.g. the past form er betrat 'he stepped in") or Polish w- (wchodzić 'walk in') and separable prefixes such as German ein- (einlaufen 'run in(to)', with e.g. the past form er lief ein 'he ran in"). ${ }^{8}$ See Blomberg (2014) for detailed descriptions of such patterns for the Swedish, French and Thai data.
} 
Benjamin Fagard et al.

(14) Frequency of MANNER (55 scenes) in all 6 languages

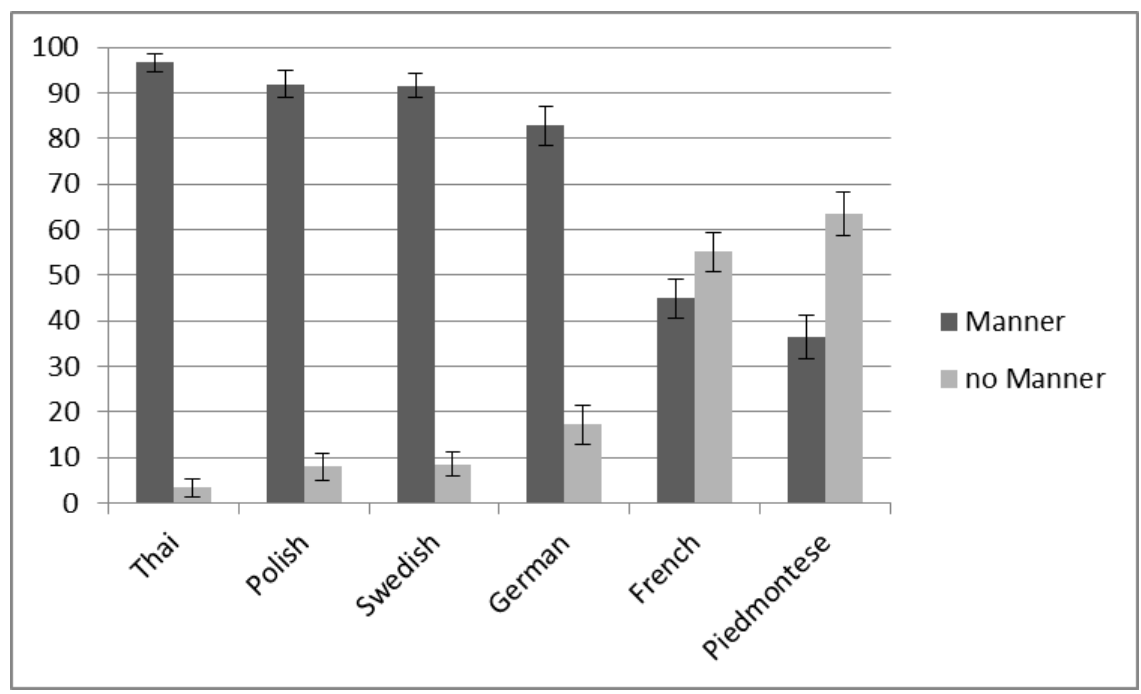

Thai not only patterned with the SF languages, but appeared closer to Swedish and Polish than the latter two to German.

Distinguishing between stimuli (i.e. scenes) where MANNER was (a) of marked kind, i.e. running, jumping or a combination of these, and (b) unmarked -when the person 'simply' walked- we could confirm that the difference in MANNER expression between SF and VF languages concerned primarily (b), as shown in (15).

(15) Frequency of MANNER depending on scene type: marked (14 scenes) vs. unmarked (41 scenes) in all 6 languages

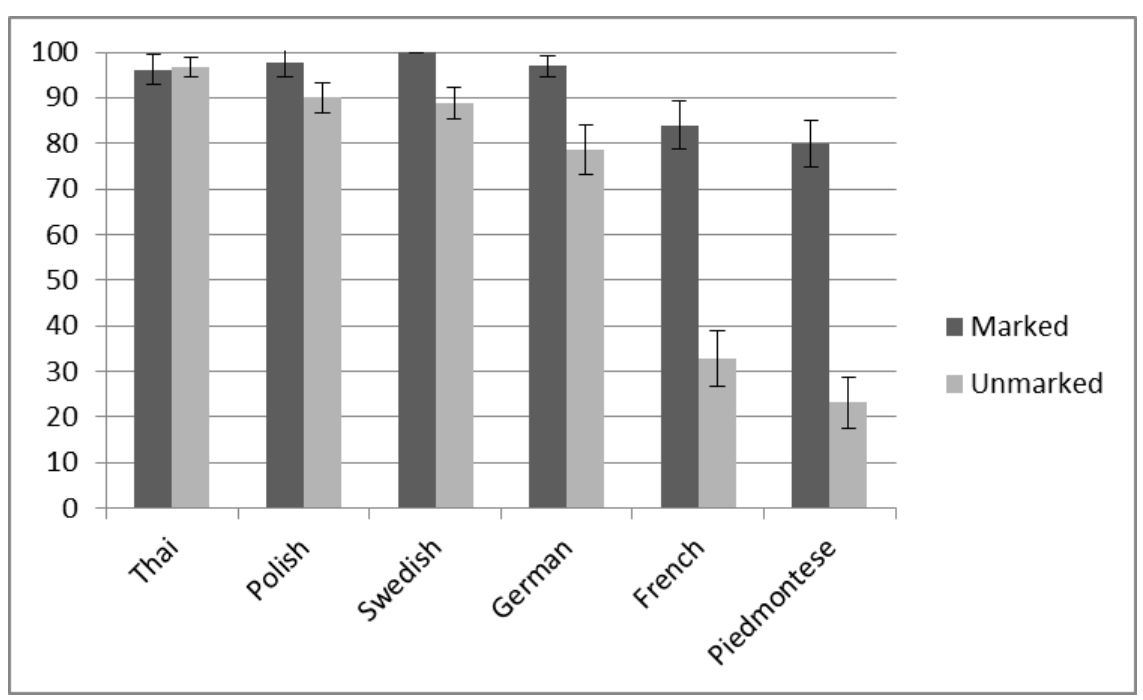




\section{The Expression of Motion Events}

In other words, stimuli with marked MANNER typically elicited data with manner verbs both in VF and SF languages (e.g. (16)-(18)).

(16)
chtopiec $w$ - biega
do morza
(Polish)
boy.NOM in- run.3SG.M to sea.GEN

'The boy is running into the sea' (traj059_pol02)

(17) en kvinna springer från ett träd mot kameran (Swedish) INDF woman run from INDF tree towards camera.DEF

'A woman runs from a tree towards the camera' (traj033_swe06)

\begin{tabular}{|c|c|c|c|c|c|}
\hline (18) an & & & $a$ & cur & (Piedmontese) \\
\hline INDF & little.boy & COMP & 3.SG & run & \\
\hline $\begin{array}{l}\text { andrintc } \\
\text { in }\end{array}$ & $a$ & l' & eva & & \\
\hline
\end{tabular}

'A little boy who runs into the sea' (traj059_piem09)

An important factor claimed to play a role in the VF/SF distinction is the socalled "boundary-crossing constraint", according to which manner verbs are highly restricted in VF languages when the TRAJECTOR (FIGURE) crosses a boundary, but much less so otherwise (cf. Aske 1989; Slobin \& Hoiting 1994). Our results are partly in line with this prediction: stimuli with boundary-crossing typically elicited utterances with manner verbs in SF languages (e.g. (19)-(20)), but not in VF languages (e.g. (21)).
mężczyzna wy- szedt
z $\quad$ krzaków
(Polish)
man.NOM out- walk.3SG.M.PST from bushes.GEN
'The man walked out from the bushes' (traj055_pol01)

(20) en kvinna går in $i$ en grotta

(Swedish)

INDF woman walk into in INDF cave

'A woman walks into a cave' (traj054_swe13)

(21) na fía a intrant na crota

(Piedmontese)

INDF girl COMP 3.SG enter into INDF cave

'a girl who enters a cave' (traj022_piem08)

As shown in (22), for both VF languages there was a significant difference between the two scene types (for French, $\mathrm{chi}^{2}=31, \mathrm{p}<.001$; for Piedmontese, $\left.\mathrm{chi}^{2}=39, \mathrm{p}<.001\right)$. However, there was also a significant difference for German 
Benjamin Fagard et al.

and Swedish $\left(\mathrm{chi}^{2}=52, \mathrm{p}<.001\right)$. As expected, there was no significant difference in either Polish or Thai.

(22) Frequency of MANNER depending on scene type: boundary crossing (22 scenes) and without boundary crossing ( 33 scenes) in all 6 languages

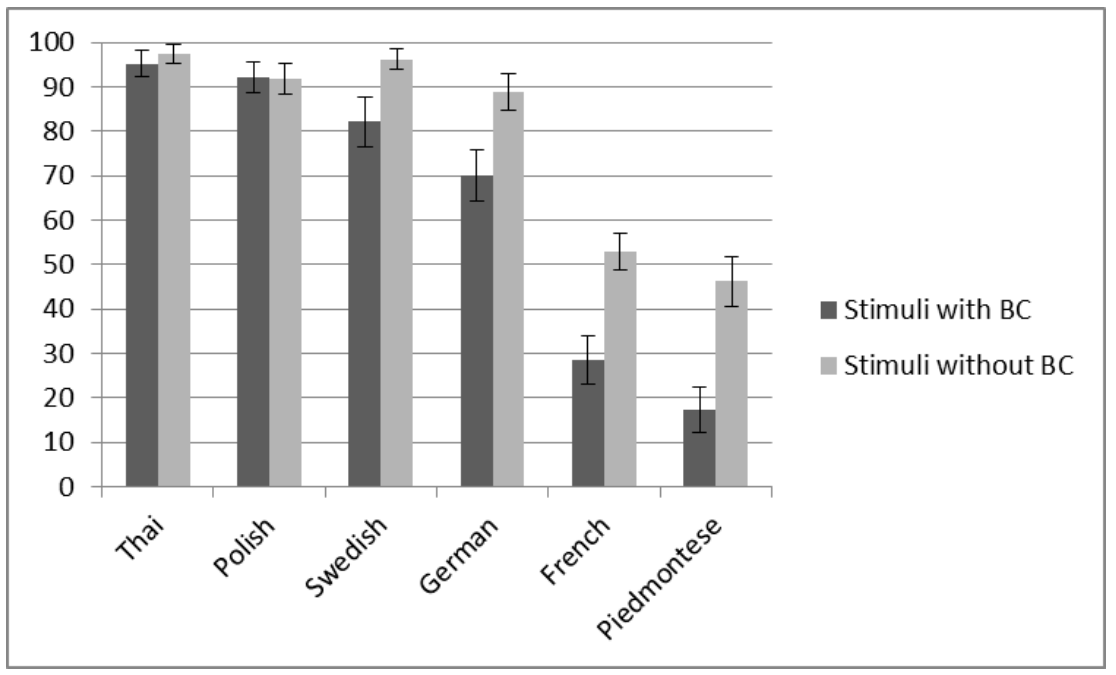

The differences we observed in patterns of expression of the PATH are not as clear-cut. PATH, it may be reminded, excludes in our analysis DiRECTION of the 'towards', 'up/down' and 'come/go' sub-types (the latter being treated under DEIXIS). We expected slight differences between SF and VF languages, but that was not the case: there was instead a significant difference between Piedmontese, French, and German on the one hand, and Swedish, Thai, and Polish on the other (the least significant of these differences being between German and Swedish: $\mathrm{chi}^{2}=18.5, \mathrm{p}<.001$; this difference is due in turn mostly to the difference of frequency of PATH expression in median scenes, with $\operatorname{chi}^{2}=15, \mathrm{p}<.001$ ).

DEIXIS was expressed much less frequently than either PATH or MANNER: the mean expression across speakers and languages was $12.6 \%$ (counting only verbs denoting motion towards the $\mathrm{DC}$, which are its most frequent expression), against $74.8 \%$ for PATH and $78.6 \%$ for MANNER. As expected, Thai had a higher proportion of (verbally expressed) DEIXIS than all other languages, especially concerning the frequency of $m a$ 'to come'.

As shown in (26), which presents the frequency of verbs denoting motion towards or away from the DC in the descriptions of scenes in which there was motion either toward the speaker/viewer (FRONT), away (BACK) or sideways (SIDE), five of the languages present unexpected patterns, quite contrary both to the standard divisions of motion event typology and to genealogical relations (Polish was excluded from this analysis due to the lack of deictic verbs.) There was, for instance, a very high frequency of verbs denoting motion towards the DC 


\section{The Expression of Motion Events}

(23) Frequency of PATH depending on scene type: Begin (14 scenes), Middle (16 scenes), End (15 scenes) in all 6 languages

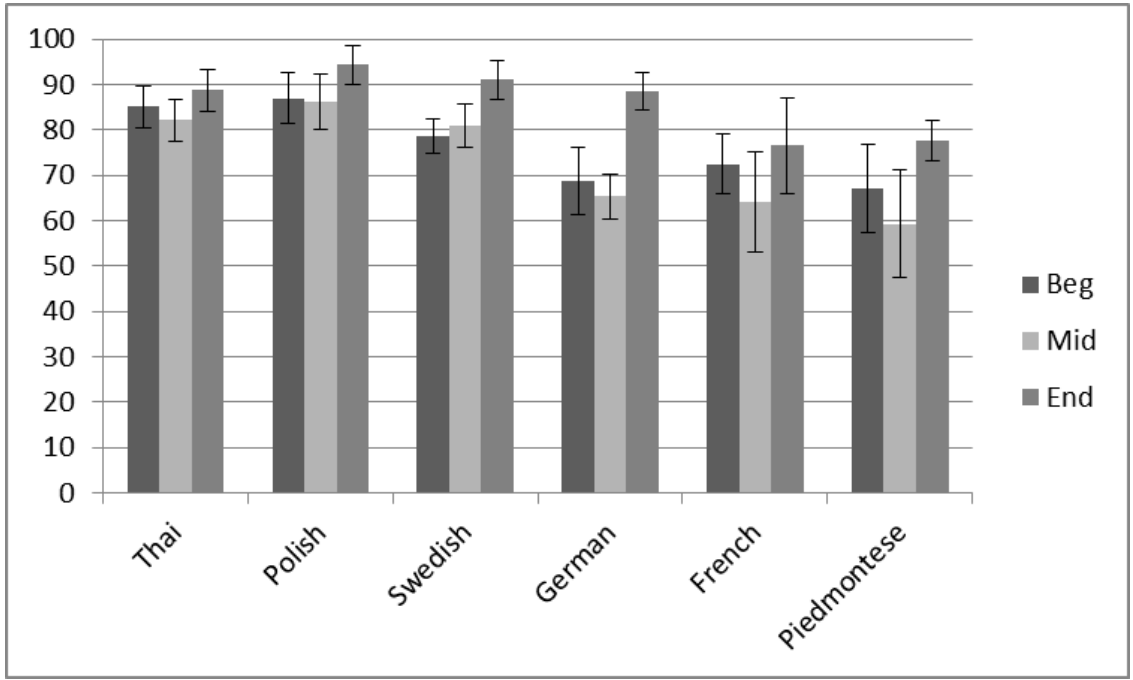

in FRONT scenes in Thai and German, as in (24), and of verbs denoting motion away from the DC in BACK scenes in Swedish and Thai.

(24) eine junge Frau die wir von vorne sehen (German) INDF.F young.F woman COMP.REL.F 1PL from front see.1PL

kommt von einem Baum

come.3PL from INDF.DAT tree

'A young woman comes from a tree, facing us' (traj032_ger08)

However, the congruence of verbs denoting motion towards the DC and FRONT scenes, on the one hand, and of verbs denoting motion away from the DC and BACK scenes, on the other, is not complete, and depends on the language. It is most obvious for Thai, slightly less for Swedish and German, and least so for Piedmontese and French, where venir was regularly used in BACK scenes as part of a more complex construction, introducing the infinitive with a partly aspectual meaning, as in (25).

(25) là il vient la réveiller

(French)

there 3SG come.3SG 3SG.F.ACC wake-up.INF

'this time he comes to wake her up' (traj036_fr11) 


\section{Benjamin Fagard et al.}

(26) Frequency of verbs denoting motion towards (COME) or away from (GO) the DC depending on scene type: BACK (18 scenes), FronT (18 scenes), SIDE (24 scenes) in 5 languages

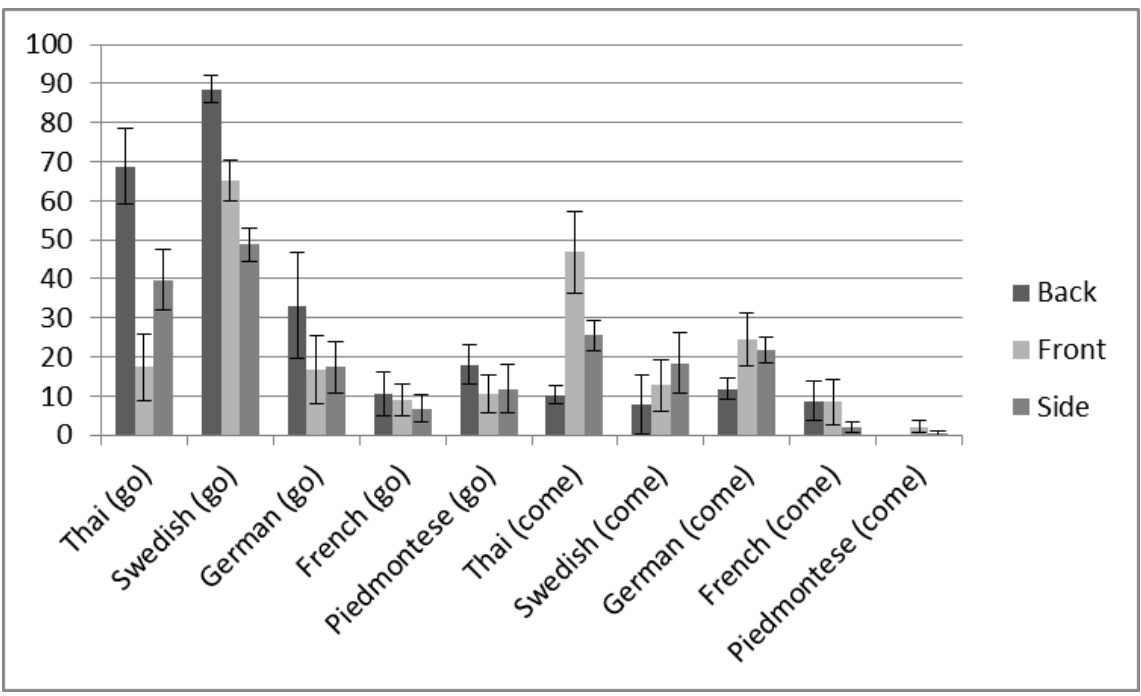

(27) Frequency of verbs denoting motion towards the DC ('come') in four different scene types: FRONT with BC (14 scenes); FRONT without BC (12 scenes); BACK with BC (9 scenes); BACK without BC (17 scenes), in 5 languages

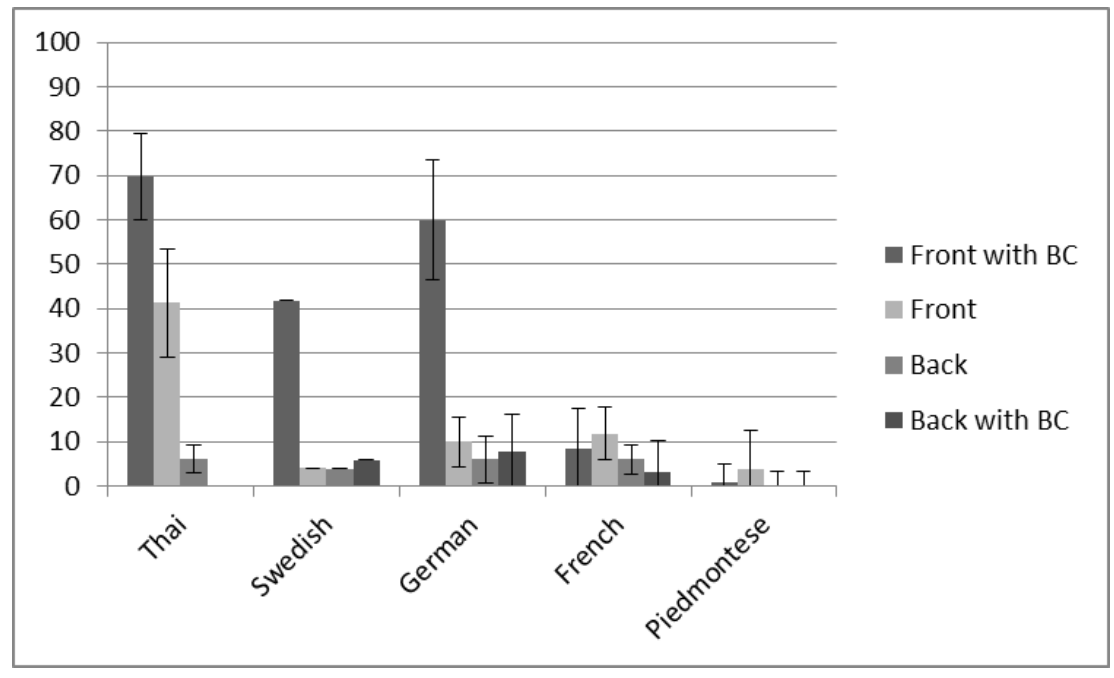

Looking more closely at the data, we checked for an effect of boundarycrossing on the use of verbs denoting motion towards the DC, trying to understand why participants used them in scenes without motion towards the camera. The graph in (27) shows that there was a very high correlation between 


\section{The Expression of Motion Events}

appearance on the screen and the use of such verbs, especially in Thai, German, and Swedish. For French and Piedmontese, there was no such effect.

This could be explained by the importance of boundary-crossing in these two languages: though scenes with motion towards the DC and boundary-crossing could elicit more use of deictic verbs, they seem to trigger the use of PATH verbs in VF languages, thus possibly countering the effect we observed in SF languages and Thai. Besides, in French, a number of utterances with deictic verbs are found in scenes where the figure moves away from the camera: in these cases, the explanation is probably the existence of a secondary deictic center.

\section{$5 \quad$ Conclusions and further research}

Returning to the questions that we began with, we can see that the results from our study are in part supportive and in part problematic for both the Talmyan (two type) and the Slobinian (three type) approaches to motion event typology. MANNER seems to be a good indicator to classify a language as VF or SF. Thai, despite expressing PATH in verbs rather than satellites, appears in this respect much more similar to the SF than to the VF type. This is also consistent with the alternative motion event typology proposed by Bohnemeyer et al. (2007), on the basis of the number of "ground elements" (landmarks) that a language-type allows in a single clause; in this respect as well, serial-verb languages like Thai belong together with typical SF languages.

PATH expression was found not to differ significantly between VF and SF languages, but between Piedmontese, French, and German on the one hand and Swedish, Thai, and Polish on the other. It should be noted again how essential the definitional aspects are, since our results are contingent on distinguishing PATH from DIRECTION, with motion DEIXIS being a special kind of the latter.

With respect to DEIXIS, we found that Thai participants, as expected, used deictic verbs more frequently than the other languages. But German and Swedish participants, especially in describing boundary-crossing (BC) scenes, were not far behind (see (27)). French and Piedmontese speakers used very few deictic verbs in boundary-crossing contexts, as could be expected, and Polish speakers did not mark DEIXIS at all, lacking full-fledged deictic verbs.

This brings us to the question of continua. While particular semantic categories such as MANNER and DEIXIS can be seen as providing the dimensions for arranging languages on a cline, our limited study suggests that the languages along these dimensions do not align. Further, some of the distinctions, such as the expression of DEIXIS in boundary-crossing contexts, seem more qualitative (without being 'discrete') than quantitative. This seems to be in contradiction with currently popular suggestions of lack of clear boundaries and all-pervasive gradualness. 


\section{Benjamin Fagard et al.}

Finally, our findings of different patterns for MANNER, PATH, and DEIXIS are consistent with proposals that motion event typology should be performed on the basis of separate constructions or strategies, rather than on language as a whole. However, this should not be interpreted as meaning that "there are no language types"; after all, constructions are not 'atoms' that a language can pick or leave at will. The next step of our investigation, conjoining form-classes and semantic categories in various conflation and distribution patterns, will hopefully contribute to a better understanding of the parameters of constructional co-variation.

\section{Acknowledgments}

This work stems from three research projects: ET (From Space to Time), Trajectoire, and CCS (Centre for Cognitive Semiotics, a six year research program, 2009-2014). These projects received financial support from the following institutions, respectively: TransferS (Investissements d'avenir ANR-10IDEX-0001-02 PSL* \& ANR-10-LABX-0099, France), TUL (Fédération de Typologie et Universaux Linguistiques, CNRS, France), and Riksbankens Jubielumsfond, Sweden. We would also like to thank heartily all participants, as well as the colleagues who helped us conduct the experiments on site in Torino, Tübingen, Paris, Louvain-la-Neuve, Montreal, Kraków and Lund.

\section{References}

Aske, Jon. 1989. Path Predicates in English and Spanish: A Closer Look. In Proceedings of the Fifteenth Annual Meeting of the Berkeley Linguistics Society, 1-14, Berkeley: Berkeley Linguistics Society.

Beavers, John, Beth Levin, and Shiao Wei Tham. 2010. The Typology of Motion Expression Revisited. Journal of Linguistics 46(3):331-377.

Berman, Ruth A., and Dan I. Slobin. 1994. Relating events in narrative: $A$ crosslinguistic developmental study. Hillsdale, NJ: Lawrence Erlbaum Associates.

Blomberg, Johan. 2014. Motion in Language and Experience : Actual and Nonactual motion in Swedish, French and Thai. Travaux de l'Institut de linguistique de Lund, 53. The Faculties of Humanities and Theology. Dissertation.

Bohnemeyer, Jürgen, Nick J. Enfield, James Essegbey, Iraide Ibarretxe-Antuñano, Sotaro Kita, Friederike Lüpke, and Felix K. Ameka. 2007. Principles of Event Representation in Language: The Case of Motion Events. Language 83(3): 495532.

Croft, William, Johanna Barðdal, Willem B. Hollmann, Violeta Sotirova, and Chiaki Taoka. 2010. Revising Talmy's Typological Classification of Complex Event Constructions. In H.C. Boas, ed., Contrastive Studies in Construction Grammar, 201-235, Amsterdam: John Benjamins. 


\section{The Expression of Motion Events}

Fortis, Jean-Michel, Colette Grinevald, Anetta Kopecka, and Alice Vittrant. 2011. Introduction. Cahiers de Faits de Langues 3:33-41.

Iacobini, Claudio. 2012. Grammaticalization and Innovation in the Encoding of Motion Events. Folia Linguistica 46(2):359-386.

Ibarretxe-Antuñano, Iraide. 2009. Path salience in motion events. In J. Guo, E. Lieven, N. Budwig, S. Ervin-Tripp, K. Nakamura and S. Özçalişkan, eds., Crosslinguistic Approaches to the Psychology of Language: Research in the Tradition of Dan Isaac Slobin, 403-414, New York: Psychology Press.

Imbert, Caroline, Colette Grinevald, and Anna Sörés. 2011. Pour une catégorie de 'Satellite' de Trajectoire dans une approche fonctionnelle-typologique. Cahiers de Faits de Langues 3:99-116.

Ishibashi, Miyuki, Anetta Kopecka, and Marine Vuillermet. 2006. Trajectoire: Matériel visuel pour élicitation des données linguistiques. Laboratoire Dynamique du Langage (CNRS / Université Lyon 2) - Fédération de Recherche en Typologie et Universaux Linguistiques, CNRS, France.

Kopecka, Anetta, and Miyuki Ishibashi. 2011. L'(a)symétrie dans l'expression de la Source et du But : perspective translinguistique. Cahiers de Faits de Langues 3:131-149.

Kopecka, Anetta. 2006. The semantic structure of motion verbs in French: Typological perspectives. In M. Hickmann and S. Robert, eds., Space in Languages: Linguistic Systems and Cognitive Categories, 83-101, Amsterdam/Philadelphia: John Benjamins.

Levinson, Steven C. 2003. Space in Language and Cognition: Explorations in Cognitive Diversity. Cambridge: Cambridge University Press.

Nakazawa, Tsuneko. 2006. Motion Event and Deictic Motion Verbs as PathConflating Verbs. In Proceedings of the 13th International Conference on Head-Driven Phrase Structure Grammar, 284-304, Stanford: CSLI.

Ricca, Davide. 1993. I verbi deittici di movimento in Europa: una ricerca interlinguistica. Firenze: La Nuova Italia Editrice.

Sinha, Chris, and Tanya Kuteva. 1995. Distributed Spatial Semantics. Nordic Journal of Linguistics 18:167-199.

Slobin, Dan I., and Nini Hoiting. 1994. Reference to Movement in Spoken and Signed Languages: Typological Considerations. In Proceedings of the Twentieth Annual Meeting of the Berkeley Linguistics Society, 487-505, Berkeley: Berkeley Linguistics Society.

Slobin, Dan I. 2004. The Many Ways to Search for a Frog: Linguistic Typology and the Expression of Motion Events. In S. Strömqvist and L. Verhoeven, eds., Relating Events in Narrative: Vol. 2. Typological and Contextual Perspectives, 219-257, Mahwah, NJ: Lawrence Erlbaum Associates.

Talmy, Leonard. 1985. Lexicalization Patterns: Semantic Structure in Lexical Forms. In T. Shopen, ed., Language Typology and Syntactic Description, vol. 


\section{Benjamin Fagard et al.}

III: Grammatical Categories and the Lexicon, 57-149, Cambridge: Cambridge University Press.

Talmy, Leonard. 1991. Path to Realization: A Typology of Event Conflation. In Proceedings of the Berkeley Linguistics Society 17, 480-519, Berkeley: Berkeley Linguistics Society.

Talmy, Leonard. 2000. Toward a Cognitive Semantics: Concept Structuring Systems, Vol 1. Cambridge, MA: MIT Press.

Wilkins, David P., and Deborah Hill. 1995. When GO means COME: Questioning the Basicness of Basic Motion Verbs. Cognitive Linguistics 6.2/3:209-259.

Zlatev, Jordan, and Peerapat Yangklang. 2004. A Third Way to Travel: The Place of Thai in Motion Event Typology. In S. Strömqvist and L. Verhoeven, eds., Relating Events in Narrative: Vol. 2. Typological and Contextual Perspectives, 159-190, Mahwah, NJ: Lawrence Erlbaum Associates.

Zlatev, Jordan. 2003. Holistic Spatial Semantics of Thai. In E. Casad and G. Palmer, eds., Cognitive Linguistics and Non-Indo-European Languages. Berlin, New York: Mouton De Gruyter.

Zlatev, Jordan. 2007. Spatial Semantics. In H. Cuyckens and D. Geeraerts, eds., The Oxford Handbook of Cognitive Linguistics, 318-350, Oxford: Oxford University Press.

Zlatev, Jordan, and Caroline David. 2003. Motion Event Constructions in Swedish, French and Thai: Three Different Language Types? Manusya 6:18-42. Zlatev, Jordan, Johan Blomberg, and Caroline David. 2010. Translocation : Language and the Categorization of Experience. In V. Evans, ed., Language, Cognition, and Space: The State of the Art and New Directions, 389-418, London: Equinox.

Benjamin Fagard

Lattice, CNRS, ENS, PSL Research University \& University of Paris 3

1 rue Maurice Arnoux

92120 Montrouge

France

benjamin.fagard@ens.fr 